\title{
LETRAMENTOS ACADÊMICOS NA PERSPECTIVA DOS GÊNEROS TEXTUAIS*
}

\author{
LITERACIAS ACADÉMICAS EN LA PERSPECTIVA DE LOS GÉNEROS TEXTUALES \\ ACADEMIC LITERACIES IN THE PERSPECTIVE OF GENRE
}

\author{
Benedito Gomes Bezerra** \\ Universidade de Pernambuco - UPE, Garanhuns, BR
}

\begin{abstract}
RESUMO: Admitindo-se que o sucesso dos estudantes em cursos de pós-graduação depende de sua capacidade de compreender e produzir os gêneros requeridos pelo ambiente acadêmico, o trabalho tem como objetivo investigar a contribuição desses cursos para o letramento dos estudantes em gêneros acadêmicos. Busca-se ainda discutir a relação entre a expectativa dos alunos e a capacidade efetivamente adquirida de produzir e compreender gêneros como resumos, resenhas, projetos de pesquisa e monografia. Para atingir os objetivos propostos, dois procedimentos foram adotados: primeiro, foram aplicados questionários a alunos de um curso de especialização em ensino de língua portuguesa. Depois, analisou-se um corpus de 10 monografias de conclusão do curso, com os respectivos rascunhos, de modo a refletir o processo de construção. Os resultados indicam que, apesar do contato com diversos gêneros acadêmicos, os estudantes encontram significativas dificuldades, em especial na escrita, sendo o exemplo mais crítico a produção da monografia de conclusão.

PALAVRAS-CHAVE: letramento acadêmico; gênero textual; leitura; escrita.
\end{abstract}

RESUMEN: Admitiéndose que el éxito de los estudiantes en cursos postgrado depende de su capacidad de comprender y producir los géneros requeridos por el ambiente académico, el trabajo tiene como objetivo investigar la contribución de esos cursos para la literacia de los estudiantes en géneros académicos. Se busca, también, discutir la relación existente entre la expectativa de los alumnos y la capacidad efectivamente adquirida de producir y comprender géneros como resúmenes, reseñas, proyectos de investigación y monografía. Para lograr alcanzar los objetivos propuestos, dos procedimientos adoptados fueron: en primer lugar, se aplicaron cuestionarios a alumnos de un curso de especialización en enseñanza de lengua portuguesa. Después, se analizó un corpus de 10 monografías de conclusión del curso, con los respectivos borradores, de modo a reflexionar sobre el proceso de construcción. Los resultados muestran que, a pesar del contacto con diversos géneros académicos, los estudiantes tienen dificultades importantes, sobre todo en la redacción, siendo el ejemplo más crítico la producción de la monografía de conclusión de la carrera.

PALABRAS-CLAVE: literacia académica; género textual; lectura; escrita.

ABSTRACT: Assuming that the success of students in graduate courses depends on their skill to understand and produce the genres required by the academic setting, this work aims to investigate to what extent these courses contribute to the literacy of students in academic genres. It still discusses the relationship between students' expectations and the effectively acquired ability to produce and understand genres such as summaries, reviews, research projects and monographs. To answer the questions that guided this research, two procedures were adopted: first, questionnaires were administered to students from a specialization course on teaching of Portuguese language. Then, we analyzed a corpus of 10 monographs for completion of the course, with their respective drafts, to reflect the construction process. The results indicate that, despite contact with various academic genres, students encounter significant difficulties, especially in writing, the most critical example being the production of the monograph for course completion.

KEYWORDS: academic literacies; genre; reading; writing.

\section{INTRODUÇÃO}

Diversos estudos sobre os letramentos no ensino superior quer se voltem para cursos de graduação quer para a pós-graduação lato e stricto sensu, dão conta de que não é simples para os estudantes se apropriarem de novas práticas de leitura e escrita tão somente pelo fato de haverem sido promovidos a esses níveis de ensino. Trata-se de práticas complexas que envolvem a orientação do aluno para o desenvolvimento de múltiplas competências, numa complexa inter-relação entre aspectos linguísticos, cognitivos e socioculturais.

\footnotetext{
*Este trabalho está vinculado ao projeto de pesquisa "Letramentos acadêmicos e gêneros textuais: práticas de leitura e escrita no ensino superior", financiado pelo CNPq, Processo nº. 471957/2010-0.

**E-mail: beneditobezerra@yahoo.com.br.
} 
Na concepção de Lea e Street, filiados aos assim chamados Novos Estudos de Letramento, "a aprendizagem no ensino superior implica a adaptação a novas formas de saber: novas maneiras de compreender, interpretar e organizar o conhecimento" (1998, p. 157). Essas novas maneiras não estão dadas no aparato cognitivo do aluno, nem são adquiridas automaticamente no contato com o mundo acadêmico. Ainda assim, chama a atenção o fato de que, por mais importante que essa nova forma de conhecer se apresente para a academia e por mais que envolva a produção e recepção de gêneros textuais bastante complexos e específicos do contexto acadêmico, tudo indica que nem sempre se reserva espaço e tempo específicos para o seu ensino no currículo dos diversos cursos.

Embora não seja garantido aos alunos o ensino explícito das questões que envolvem os letramentos acadêmicos, representadas, por exemplo, pela capacidade de lidar com novos gêneros textuais, o domínio desses gêneros, conforme atesta Hoffnagel, "é considerado pelos professores como importante para que o aluno possa ter êxito não só no curso, mas na sua vida profissional” (2010, p. 278).

A tarefa com que se deparam os estudantes, em suas práticas de leitura e escrita na universidade, é descrita por Bartholomae nos seguintes termos:

Cada vez que se senta para escrever para nós, o aluno tem que inventar a universidade para aquela circunstância - inventar a universidade, ou seja, uma ramificação dela, como História, Economia, Antropologia ou Inglês. Ele tem que aprender a falar nossa linguagem, falar como falamos, experimentar formas específicas de saber, selecionar, avaliar, relatar, concluir e argumentar que definem o discurso de nossa comunidade (1985, p. 273).

Embora já bastante complexa, essa primeira caracterização descreve o problema de forma ainda otimista. Na continuação de seu argumento, o autor pondera ainda que, na verdade, os alunos são forçados a lidar com diversos discursos e não apenas com um único, ao escrever e ler no âmbito de determinada disciplina na universidade. De fato, segundo Bartholomae, o aluno "precisa atuar em campos cujas normas reguladoras da apresentação de exemplos ou do desenvolvimento de uma argumentação são, até mesmo para o profissional, ao mesmo tempo distintas e misteriosas" (p. 273). Ao ingressar na universidade ou ao mover-se, dentro dela, da graduação para a pós-graduação, o aluno tipicamente necessita da assistência de seus professores para ajudá-lo a compreender e bem lidar com essas normas "misteriosas".

Assim é que, segundo defende Johns (1997), os professores universitários deveriam se perguntar: "Qual é o nosso papel em ajudar os alunos a resolver os 'mistérios' acadêmicos? Que podemos fazer para tornar as tarefas ligadas aos letramentos acadêmicos mais fáceis de manejar? Como podemos ajudá-los a 'inventar' textos de forma adequada e pessoalmente satisfatória em contextos acadêmicos?”

Que esse não é um problema apenas de graduandos, atesta o trabalho de Figueiredo e Bonini (2006, p. 413), ao se reportar à "dificuldade de muitos mestrandos em ingressar no discurso acadêmico em termos práticos". Citando como exemplo o artigo de pesquisa, os autores afirmam que muitos de seus alunos "mostram pouca (ou nenhuma) familiaridade com e capacidade de utilização eficiente dos gêneros do discurso científico", embora tenham conseguido ingressar em um programa de pós-graduação stricto sensu.

Também de acordo com os trabalhos de Swales (por exemplo, 1990 e 2004), o sucesso dos estudantes em cursos de pós-graduação bem como na carreira acadêmica como tal, depende amplamente de sua capacidade de ler/compreender e produzir os gêneros textuais requeridos por esse ambiente, quer sejam eles gêneros mais públicos e prestigiados ou os chamados gêneros oclusos (occluded genres)1.

Considerando essa questão, o presente artigo tem como objetivo investigar até que ponto um curso de especialização (pós-graduação lato sensu) em língua portuguesa, em que os estudantes necessariamente

\footnotetext{
${ }^{1}$ Por exemplo, um parecer sobre um artigo, embora desempenhe um importante papel no processo a que se destina, tipicamente não desfruta de visibilidade compatível com sua relevância, como é o caso do artigo em si.
} 
travam contato com gêneros textuais típicos do ambiente universitário, contribui de modo específico para o letramento dos estudantes em gêneros acadêmicos. Busca-se ainda discutir a relação entre a expectativa dos alunos que, ao ingressarem no curso, frequentemente manifestam o desejo de se prepararem para o mestrado ou ainda de consolidar os conhecimentos adquiridos na graduação e assim incrementar sua prática como professores, e a capacidade efetivamente adquirida de produzir e compreender gêneros acadêmicos tais como resumos, resenhas, projetos de pesquisa e monografia, entre outros.

\section{CENÁRIO DA PESQUISA E ASPECTOS METODOLÓGICOS}

O curso referido neste estudo foi ofertado pela Universidade de Pernambuco (UPE) entre os anos de 2008 e 2010, em três turmas que funcionaram respectivamente nas cidades de Caruaru, Garanhuns e Salgueiro, e teve como público principal professores de língua portuguesa, egressos da própria UPE ou de outras instituições, em geral localizadas no interior dos estados de Pernambuco e de Alagoas. Organizado em uma estrutura modular, o curso teve suas aulas funcionando em finais de semana alternados por um período de nove meses, após os quais se seguiu um período de orientação de quatro meses, finalizando-se o processo com a apresentação pública das monografias de conclusão diante de uma banca constituída pelo orientador e por um professor examinador.

Na tentativa de responder às indagações que nortearam a pesquisa, dois procedimentos foram privilegiados. Primeiramente, foi solicitado aos alunos que respondessem a um questionário, cujas questões se reportavam centralmente à experiência que tiveram, ao longo do curso, com práticas de escrita e leitura envolvendo diversos gêneros textuais. Para os fins deste trabalho, selecionamos para análise uma amostra de 15 questionários provenientes das três turmas.

O segundo procedimento consistiu na coleta e análise de um corpus de 10 projetos de pesquisa, representados pelos respectivos e consequentes rascunhos da monografia de conclusão do curso então em construção. Nessa etapa de análise textual, procuramos acompanhar e identificar, tomando como exemplo o projeto de monografia e a própria monografia de conclusão do curso, as dificuldades eventualmente manifestas nos textos dos alunos durante o processo de construção de ambos os gêneros.

Para fundamentar a pesquisa, adotamos os aportes teóricos ligados aos Novos Estudos do Letramento, especialmente no que diz respeito às perspectivas possíveis para o tratamento da escrita (e da leitura) do estudante no ensino superior (LEA; STREET, 1998, 2006), e abordamos a questão dos letramentos acadêmicos a partir da categoria de gênero textual conforme desenvolvida por Johns (1997), seguindo a perspectiva da linguística aplicada, associada à obra de John Swales (1990, 2004), sem necessariamente limitar-se a ela.

\section{MODELOS BÁSICOS DE LETRAMENTO E LEITURA/ESCRITA DOS ALUNOS NO ENSINO SUPERIOR}

Ao definir e optar pelo termo letramento, Johns (1997, p. 2) argumenta que ele tem a vantagem de ser mais inclusivo do que a simples expressão "leitura e escrita". De acordo com a autora, o conceito de letramento abrange "modos de conhecer determinados conteúdos, linguagens e práticas" e se refere a "estratégias para a compreensão, discussão, organização e produção de textos", além de estar relacionado com "o contexto social em que o discurso é produzido e com os papéis e comunidades a que pertencem leitores e produtores de textos". Como tal, a noção de letramento ainda engloba "tanto os processos como os produtos da aprendizagem, tanto a forma como o conteúdo e os papéis e propósitos tanto de leitores como de produtores de textos". Assim, conforme a descrição da autora, o termo letramento se mostra evidentemente complexo e eventualmente problemático, uma vez que procura "integrar em um só conceito as numerosas e variadas 
influências sociais, históricas e cognitivas que pesam sobre leitores e escritores em sua tentativa de processar e produzir textos".

Um aspecto da complexidade da noção de letramento é que se trata de múltiplos letramentos e não de um letramento único e universal. Conforme Johns, se desejamos discutir letramento, "então o termo deve ser pluralizado ('letramentos'), pois existem diversos letramentos, especialmente em contextos acadêmicos, [e esses letramentos são] adquiridos de diferentes maneiras e para diferentes fins" (1997, p. 3). Por exemplo, não é comum lidarmos com textos literários e com textos da área de engenharia com idêntica desenvoltura. Os letramentos, portanto, são complexos e decididamente plurais.

Na concepção de Street (1984), há dois modelos básicos de letramento: o modelo autônomo e o ideológico. No modelo autônomo de letramento, pressupõe-se que o mero domínio das habilidades de ler e escrever são suficientes para habilitar a pessoa a resolver satisfatoriamente todas as situações postas por uma sociedade letrada. De acordo com Russell et al. (2009), o modelo autônomo concebe o letramento como uma habilidade descontextualizada e única, passível de ser transferida de um contexto para outro sem grandes dificuldades. Já o modelo ideológico põe em relevo "a natureza contextual e social das práticas de letramento e as relações de poder e autoridade que estão subentendidas em qualquer evento de letramento” (p. 399).

Conforme Marcuschi (2001), a adesão a uma concepção como o modelo ideológico de letramento é parcialmente inevitável, pois hoje não seria mais possível investigar questões relativas às práticas da leitura e da escrita na sociedade "permanecendo apenas no aspecto linguístico sem uma perspectiva crítica, uma abordagem etnograficamente situada e uma inserção cultural das questões nos domínios discursivos” (p. 2). O modelo ideológico tem a vantagem de dedicar mais atenção ao "papel das práticas de letramento na reprodução ou na ameaça das estruturas de poder na sociedade” (p. 4).

Apesar de endossar parcialmente o modelo ideológico de letramento, especialmente por permitir um questionamento da tese da autonomia e supremacia da escrita sobre a fala, ou do letramento sobre a oralidade, Marcuschi (2001) se mostra cauteloso com os "fortes apelos ideológicos" da proposta e evita concordar com a "Escola de Lancaster" em tratar o letramento como uma questão apenas social e política. Para o autor, o modelo adequado para abordar os problemas do letramento poderia ser assim delineado:

É o que parte da observação das relações entre a oralidade e o letramento na perspectiva do contínuo das práticas sociais e atividades comunicativas, envolvendo parcialmente o modelo ideológico (em especial o aspecto da inserção da fala e da escrita no contexto da cultura e da vida social) e observando a organização das formas linguísticas no contínuo dos gêneros textuais (MARCUSCHI, 2001, p. 4).

Essa concepção se mostraria flexível o bastante tanto para evitar uma concentração dos estudos nas formas linguísticas, afastando-se do modelo autônomo do letramento, como para não colocar as questões ideológicas em posição central, dissociando-se dos extremos do modelo ideológico. Em suma, Marcuschi postula uma visão que não se apoie em "modelos estratificados e alienados da realidade sócio-comunicativa" (2001, p. 4), que justifiquem um foco exclusivo nas estruturas linguísticas ou que se concentrem apenas nas questões sociais. Seria um modelo moderado e intermediário entre os modelos autônomo e ideológico, com uma forte ênfase na relação entre fala e escrita como práticas sócio-discursivas complexas e aliada a uma perspectiva do contínuo dos gêneros textuais tanto orais como escritos.

Contudo, independentemente do mérito da proposta, um olhar sobre os atuais estudos do letramento, inclusive no ambiente acadêmico, provavelmente revelará que a escrita ainda mantém o status de objeto privilegiado de investigação e ensino, e muito mais da perspectiva da produção textual do que da leitura e compreensão. É o que revela, por exemplo, o estudo de Dionísio e Fischer (2010), discutidos adiante.

\footnotetext{
${ }^{2}$ Referência a autores alinhados com os Novos Estudos do Letramento.
} 


\section{ABORDAGENS DA LEITURA/ESCRITA DE ESTUDANTES NO ENSINO SUPERIOR}

O alinhamento com a perspectiva do modelo ideológico conduz a uma visão, no interior dos Novos Estudos do Letramento, da escrita no ensino superior baseada em três abordagens ou modelos diferentes e eventualmente complementares. Esses modelos foram identificados por Lea e Street (1998) com base em pesquisa realizada em dois distintos contextos universitários. Conforme os autores, as abordagens à escrita estudantil no ensino superior são as seguintes: o modelo das habilidades de estudo, da socialização acadêmica e dos letramentos acadêmicos.

O primeiro modelo, das habilidades de estudo, se concentra nos aspectos formais da escrita do aluno, uma vez que o domínio das questões estruturais é visto como caminho para aquisição da capacidade de produzir satisfatoriamente os diversos gêneros acadêmicos. Não há, nessa abordagem, nenhum destaque para os aspectos sociais envolvidos no processo de escrita ou mesmo para as peculiaridades da escrita em cada campo disciplinar e sim para traços formais como a estrutura gramatical e a pontuação, por exemplo. Conforme Lea e Street (2006, p. 228), o modelo está implicitamente ligado a teorias de aprendizagem "preocupadas com a transmissão do conhecimento". Entre essas teorias, os autores citam o behaviorismo como uma das bases teóricas para o modelo das habilidades de estudo.

Já o modelo da socialização acadêmica se mostra bem mais sensível à complexidade dos desafios enfrentados pelos estudantes quando se veem diante da necessidade de produzir textos no ambiente acadêmico. Nessa abordagem, acredita-se que a exposição do aluno aos diversos gêneros acadêmicos, mediada pelo professor, é um dos caminhos para resolver os problemas do letramento na academia. A abordagem da socialização acadêmica, descrita por Lea e Street (2006) como associada a áreas tais como a sociolinguística, a análise do discurso e a teoria de gêneros, reconhece e ressalta o fato de que o conhecimento é construído de diferentes formas e através de diferentes gêneros textuais nos diversos campos disciplinares. Apesar de reconhecer a importância dos fatores contextuais em torno da escrita do estudante, "essa abordagem tende a tratar a escrita como um meio de representação transparente" (LEA; STREET, 1998, p. 158) e, desse modo, deixa de considerar as questões mais profundas envolvidas na produção de gêneros acadêmicos.

Finalmente, o modelo dos letramentos acadêmicos encara a escrita do aluno como uma prática social complexa, que requer dos estudantes mais do que o domínio de habilidades de estudo ou a socialização no ambiente acadêmico. Essa abordagem leva em consideração os modelos anteriores e acrescenta a eles uma "atenção especial às relações de poder, autoridade, produção de sentidos e identidade que estão implícitas no uso de práticas de letramento em contextos institucionais específicos” (LEA; STREET, 2006, p. 229). O modelo, portanto, se alinha a uma forma bastante crítica do conceito de letramento ideológico, propondo-se ir além do ensino de habilidades formais de escrita e questionando a validade da simples aculturação dos estudantes no ambiente universitário, conforme proposta da abordagem da socialização acadêmica.

Como se percebe, e segundo ressaltam Lea e Street (1998), as três abordagens mencionadas não são vistas como autoexcludentes. De fato, a abordagem dos letramentos acadêmicos, longe de rejeitar a validade das habilidades de estudo e da socialização acadêmica como tais, procura incorporá-las em uma concepção mais abrangente, centrada na noção de escrita como prática social complexa. Assim, ao mesmo tempo em que absorve o melhor dos dois modelos anteriores, a abordagem dos letramentos acadêmicos é tida como "a mais apta para dar conta da natureza da escrita dos estudantes na relação com práticas institucionais, relações de poder e identidades, em suma, para considerar a complexidade da produção de sentido" (RUSSELL et al., 2009, p. 400).

\section{O LUGAR DOS GÊNEROS NA PERSPECTIVA DOS LETRAMENTOS ACADÊMICOS}

No contexto atual da pesquisa sobre leitura e escrita, a categoria de gêneros textuais necessariamente se impõe como um conceito central, qualquer que seja a teoria ou modelo analítico adotado. Conforme Russell 
et al. (2009), o conceito de gêneros está implícito em cada um dos modelos propostos para abordar a escrita dos estudantes no ensino superior. $\mathrm{O}$ que muda é a perspectiva pela qual os gêneros são conceituados em cada caso. No modelo das habilidades de estudo, os gêneros são considerados a partir de seus traços formais e superficiais. No modelo da socialização acadêmica, ressalta-se a conceituação dos gêneros no interior de diferentes culturas e normas disciplinares, definidas a partir dos textos "escritos por acadêmicos de uma determinada comunidade disciplinar" (RUSSELL et al., 2009, p. 405). A perspectiva dos letramentos acadêmicos, por sua vez, "se alinha com uma visão de gênero como prática social, e não com o conhecimento de gêneros em termos da comunicação disciplinar em si, embora esta seja, por sua própria natureza, essencial para uma perspectiva de prática social” (p. 405).

Na concepção de Lea e Street (2006), um dos aspectos relevantes do modelo de letramentos acadêmicos consiste exatamente em enfatizar a importância do ensino explícito das "mudanças de gêneros e modos à medida que os alunos se movem entre trabalhos em grupo, expressão oral, tomada de notas, apresentações, escrita mais formal etc.” (p. 229). Para os autores, a relação entre práticas culturais e gêneros deve ser identificada e ressaltada no processo de letramento.

O conhecimento dos gêneros, dentro de uma perspectiva da escrita e leitura como práticas sociais, é capaz de "ajudar os alunos a desenvolver uma rica compreensão dos textos que lhes serão úteis durante sua vida acadêmica e profissional” (JOHNS, 1997, p. 21). Para Johns, o conhecimento individual dos gêneros é tanto complexo como dicotômico, uma vez que se assenta em aspectos cognitivos (conhecimentos prévios, esquemas) e sociais (compartilhados com outros leitores e escritores) e se caracteriza como retoricamente recorrente (MILLER, 2009) e dinâmico (BERKENKOTTER; HUCKIN, 1995), mas também como sistemático e convencional (BHATIA, 1993).

De acordo com Johns (1997), o conhecimento de gênero inclui saberes compartilhados sobre nomes de gêneros, propósitos comunicativos, papéis de leitores e escritores, contextos, convenções formais, conteúdos, registros, valores culturais e intertextualidade. Exemplificando a importância desses saberes e de sua construção social, uma questão apresentada pela autora provavelmente soará familiar para muitos de nós que lidamos com alunos no ensino superior, além de possivelmente nos fazer lembrar nossa própria experiência discente: "Alguns gêneros, particularmente em contextos pedagógicos, são nomeados de modo vago e quase casual. Por exemplo, quando um professor exige um 'trabalho de pesquisa', é difícil, para os alunos, determinar apenas pelo nome o que está sendo exigido" (JOHNS, 1997, p. 23). Considerando-se ainda as costumeiras variações disciplinares, a indefinição em torno dos nomes e dos respectivos significados de muitos gêneros ("pedagógicos") requeridos no ambiente acadêmico reflete-se no habitual questionamento dos alunos, seguindo-se à comunicação, por parte do professor, de que devem executar alguma tarefa e produzir algum texto: "Como é que o senhor quer [o trabalho]?"

Dionísio e Fischer (2010), em estudo sobre trabalhos acadêmicos apresentados em congresso internacional sobre a temática dos letramentos ("literacia") no ensino superior, verificam que gêneros bastante tradicionais na academia, tais como artigos científicos, resenhas, monografias e ensaios são pouco mencionados como objeto central de pesquisas. Em vez disso, o foco se concentra, por um lado, em referências generalizadas à "escrita acadêmica" ou a gêneros como "narrativas pessoais", "reflexões", "memoriais", "trabalhos", "defesa argumentativa de pontos de vista", "apontamentos" e "apresentações na sala de aula”, vale dizer, gêneros relacionados com o processo de ensino e aprendizagem.

A partir disso, as autoras propõem uma "tipificação dos textos presentes no ensino superior em dois grandes grupos: os 'gêneros científicos' e as 'ferramentas pedagógicas” (DIONÍSIO; FISCHER, 2010, p. 295). O primeiro grupo, que abrange os gêneros acadêmicos mais "profissionais", parece estar mais relacionado ao trabalho com a leitura, enquanto o segundo grupo, que abrange gêneros voltados para atividades relacionadas com a sala de aula, se refere à produção escrita e também oral. As autoras concluem que, quando se trata do contexto acadêmico, "a literacia... diz sobretudo respeito a práticas de escrita e muito menos às de leitura”. Ainda a partir dos dados da pesquisa, Dionísio e Fischer sugerem que pode 
haver um "eventual desfasamento entre o que se lê e o que se escreve na universidade, com todas as consequências para o desenvolvimento nos estudantes do repertório de práticas mais ou menos especializadas da esfera em que estão envolvidos - a científica (p. 295). A propósito disso, o já referido modelo proposto por Marcuschi (2001) vale também como uma crítica à abordagem dos letramentos acadêmicos, na pesquisa (e no ensino, quando há) como uma questão atinente quase exclusivamente à escrita.

\section{PRÁTICAS DE LETRAMENTO EM CURSOS DE ESPECIALIZAÇÃO: ANÁLISE E DISCUSSÃO}

\subsection{O curso: o que dizem os alunos}

Conforme mencionado, o curso de especialização em ensino de língua portuguesa objeto desta pesquisa foi ofertado em um sistema modular, com aulas nos finais de semana, alternados sempre por uma semana de folga. Cada disciplina, portanto, era finalizada em pouco mais do que quinze dias, sendo imediatamente seguida da próxima matéria. Diante disso, e considerando-se o estilo de vida corrido da maioria dos alunos, em geral professores de língua portuguesa, dificilmente lhes foi proposta alguma atividade que não se esgotasse no próprio espaço da sala de aula ou, no máximo, no intervalo entre o primeiro e o segundo final de semana do módulo.

Entre as atividades desenvolvidas no decorrer do curso, os alunos mencionam "interpretação de textos", "releitura de textos", "produção textual", "resumos", "apresentações de trabalhos", "discussões em grupo", "debates", "seminários", "sequência didática”, "provas escritas", "redação”, "exercícios orais e escritos", "projetos", "análises de livros didáticos", "artigo científico", "resenha” e "fichamento". O cumprimento dessas tarefas envolve leitura e escrita, ao mesmo tempo em que se percebem diversos gêneros relacionados com a oralidade.

Apesar do exposto, na opinião de uma aluna, "as práticas solicitadas pelos professores foram muito poucas". Fazendo uma síntese dessas práticas, a aluna destaca as "atividades de leituras de textos com diferentes tópicos" e "resumos sobre as aulas". A leitura de textos teóricos aparece frequentemente associada ao gênero resumo como forma de documentação. $\mathrm{O}$ resumo, com esse nome ou similares, tais como o "fichamento", parece ser o gênero da escrita mais produzido por esses estudantes e isso, ao que tudo indica, em função da leitura. Ou seja, o resumo não é praticado como exercício de escrita em si, mas como forma de verificação de leituras prescritas. Nesse sentido, alguns alunos relatam terem produzidos "numerosos" resumos ou fichamentos durante o curso.

As atividades de leitura, embora encaradas como objeto de estudo, superam em muito a prática de produção de textos acadêmicos escritos, como veremos adiante. Apesar de sua frequência como atividade do curso, o resumo não é a principal forma de verificação de leituras. Na maioria das vezes, estas são "socializadas" na forma de exposições orais ou "seminários". As atividades em grupo tendem a predominar sobre atividades individuais e a participação dos alunos é estimulada também como forma de quebrar a monotonia da fala do professor ao longo de dois dias inteiros de aula.

Presume-se que, em um curso de pós-graduação, os alunos, dando continuidade a sua formação como graduados, terão a oportunidade de conhecer e praticar diversos gêneros acadêmicos, relacionados tanto com práticas de leitura como de escrita. Especificamente, os alunos dão conta de terem lido, ao longo do curso, "capítulos de livros, poemas, letras de música, artigos científicos", charges, letras de músicas, reportagem jornalística, monografias, resenhas, resumos e anotações do professor, apresentações PowerPoint e até livros completos.

Referindo-se especificamente à escrita, os alunos afirmam terem produzido, além de resumos e fichamentos, uma resenha (na disciplina de Leitura e Produção Textual), um gênero que eles chamaram de "redação", 
poemas, apresentações PowerPoint e um artigo científico (na disciplina acima referida), além, é claro, da monografia de conclusão do curso. Essas informações permitem confirmar que as atividades de leitura realmente predominam sobre as práticas de escrita. Considerando-se que os estudos sobre letramentos se concentram bem mais na escrita, pode-se perguntar se não faz falta uma teoria de letramentos também para a leitura. É o que parecem indicar também as constatações de Dionísio e Fischer (2010).

Um aspecto provavelmente surpreendente foi a afirmação dos alunos no sentido de que a pós-graduação lato sensu não proporcionou o contato com novos gêneros, especialmente no que diz respeito à leitura. Para um estudante, houve apenas a oportunidade de "aprofundamento em gêneros acadêmicos". Em termos da produção de textos, teria havido apenas uma grande novidade, que seria a monografia de conclusão de curso. No entanto, apesar do que dizem os estudantes, não foi incomum ouvir deles, no decorrer do curso e ao longo do processo de orientação, pedidos para que os professores fossem "compreensivos", pois alguns alegavam que nunca antes, nem mesmo na graduação (por ter sido concluída há muito tempo, por exemplo), haviam produzido gêneros como o projeto de pesquisa e a monografia.

Entre as dificuldades reportadas para conclusão do curso, os estudantes citam explicitamente apenas questões relacionadas com a produção escrita de gêneros acadêmicos. Uma aluna chega mesmo a afirmar: "na leitura não senti dificuldade". Quanto à escrita, as queixas se dividem entre gêneros acadêmicos produzidos no âmbito das disciplinas e a monografia de conclusão do curso. No primeiro caso, são mencionadas as dificuldades encontradas "na produção da resenha e na construção de um artigo científico", dois gêneros que fogem ao esquema habitual das "ferramentas pedagógicas" referidas por Dionísio e Fischer (2010) e se inserem entre os "gêneros científicos". No segundo caso, isto é, no que tange à produção da monografia, os estudantes mencionaram especialmente dificuldades com "a estrutura [do trabalho]" e com "a compreensão das normas da ABNT". Segundo uma aluna, o problema é que as normas da ABNT foram “cobradas superficialmente em algumas disciplinas". Continuando seu comentário, a aluna recorda que "durante a graduação, a cobrança também foi superficial, onde tanto o orientador quanto o professor da disciplina de prática não se fizeram muito presentes". Portanto, neste caso, a própria aluna assume uma perspectiva de déficit, que atribui a falhas da graduação, representadas pelo não cumprimento do papel do professor em ensinar (ou cobrar) as referidas normas, facilitando a socialização dos estudantes através daquele gênero acadêmico. Fugindo ao foco nos aspectos formais, uma aluna reporta como principal dificuldade a análise do corpus de sua pesquisa, pois, de acordo com ela, "não soube sistematizar as informações relevantes para comprovar a pesquisa realizada".

Em face das dificuldades e demais vicissitudes do curso, os alunos, diante de uma questão sobre "o grau de contribuição do curso para o seu letramento em gêneros acadêmicos", dividiram-se entre os que pensam que a contribuição foi "significativa" e aqueles segundo os quais o curso "contribuiu pouco". Percebe-se que, ao final do curso, os alunos não se sentem completamente seguros sobre os progressos realizados em lidar com a escrita e a leitura de gêneros acadêmicos. A escrita, particularmente, parece constituir-se ainda como uma fonte de permanentes dificuldades e obstáculos.

\subsection{A monografia de conclusão do curso: o que mostram os textos}

Apesar de que a maioria dos pós-graduandos já teve a oportunidade de elaborar uma monografia, o chamado Trabalho de Conclusão de Curso (TCC), ao final do curso de graduação, a tarefa parece se apresentar, em muitos aspectos, como nova para eles. Um dos primeiros problemas que se observa, desde a fase do projeto, diz respeito à pouca compreensão do que seja de fato um trabalho de pesquisa. No dia a dia do ensino nos níveis fundamental e médio, os pós-graduandos, no papel de professores, sabem aparentemente muito sobre projetos de intervenção que buscam solucionar alguma deficiência notada no ambiente escolar. Essa postura intervencionista, precedida de pouca ou nenhuma análise e reflexão, transparece na descrição de vários trabalhos de pesquisa. Veja-se como a autora inicia o resumo numa versão preliminar de sua monografia, cujo título era Análise do gênero textual reportagem no livro didático: 
Esta pesquisa apresenta uma proposta de ensino utilizando a oralidade e a escrita a partir de um gênero textual específico: a reportagem, uma vez que o ensino hoje se exige a multidisciplinaridade como ferramenta primordial no processo de ensino- aprendizagem.

Como sugere o título, a pesquisa nada tinha a ver com a apresentação de uma "proposta de ensino" e muito menos com a oralidade. Ao lado da confusão entre fazer pesquisa como produção de conhecimento e elaborar propostas de intervenção no ambiente escolar, avultam questões conceituais e de estruturação de um raciocínio claro e bem definido: é difícil dizer que relação há entre uma "proposta de ensino utilizando a oralidade e a escrita" e o "gênero textual específico: a reportagem", além da dificuldade em aceitar a "multidisciplinaridade” como explicação para essa perspectiva.

Um segundo problema revelado pelos textos dos alunos diz respeito à dificuldade em lidar com informações advindas de fontes bibliográficas consultadas. Uma coisa é o plágio em si, muitas vezes detectado na escrita dos alunos. Outra é a aparentemente incapacidade dos alunos em citar adequadamente os autores lidos. Na interação com os alunos, percebemos que a paráfrase ou quase cópia de segmentos textuais de autores pesquisados pode resultar da pouca familiaridade com as técnicas de citação e não necessariamente de má fé por parte do aluno.

Já se tornou trivial a ideia de que os gêneros textuais são fenômenos históricos, profundamente vinculados à vida cultural e social. Os gêneros contribuem para ordenar e estabilizar as atividades sóciocomunicativas do dia-a-dia se inova na interlocução com a introdução de novas tecnologias.

O trecho, que lembra imediatamente uma passagem de um dos textos de Marcuschi, retornou para a aluna com a instrução do professor, aposta à margem, indicando: "dar o devido crédito a Marcuschi, aqui". Por esse exemplo, o plágio não aparece como algo simples e de pacífica interpretação. Os alunos frequentemente utilizam material de terceiros como se estivessem simplesmente resumindo o conteúdo do texto lido, influência, talvez, da reiterada prática de produzir os gêneros "resumo" e o correlato "fichamento". Habituados a essa prática, aparentemente não sabem como usar o material citando de acordo com as normas e a ética da pesquisa.

Uma questão ainda mais preocupante é a limitação demonstrada no que tange à capacidade de análise dos dados da pesquisa e ainda mais quando se trata de estudos com corpora de textos produzidos por alunos. A mudança de gênero envolvida na passagem da avaliação de textos produzidos em situação escolar para a análise desses mesmos textos no cenário de uma pesquisa acadêmica parece trazer grandes dificuldades para os alunos, conforme já estabelecido por Lea e Street (1998).

Numa pesquisa sob o tema Coerência textual nas produções do $9^{\circ}$. ano do Ensino Fundamental na escola pública, a aluna elegeu como corpus um conjunto de 20 textos produzidos no âmbito da disciplina de língua portuguesa. Embora o trabalho não deixe claro, aparentemente a professora era a própria pesquisadora. A proposta de produção textual consistia na seguinte instrução: "Escreva uma narração a partir da seguinte frase dando continuidade e escolha um título: 'O maior sonho da minha vida será...”. As evidentes inadequações contidas na proposta não merecem, por parte da aluna, qualquer comentário crítico no processo de análise.

Primeiramente, seria mais adequado, à luz dos atuais estudos do texto, solicitar a produção de um gênero específico e não de um tipo textual ("narração"), ou ainda estabelecer que a narração poderia tomar a forma de um gênero de preferência dos alunos. O caráter anacrônico da proposta, do ponto de vista dos desenvolvimentos em Linguística Textual e até mesmo diante das diretrizes oficiais de ensino, não é absolutamente contemplado na análise da aluna-pesquisadora. Além disso, a frase que deveria ser continuada fala de um sonho que "será", como se fosse um sonho que as pessoas teriam no futuro. A pesquisadora não viu problema nisso, mas é razoável pensar que ela poderia sugerir algo como "o maior sonho da minha é..." como uma proposta de escrita mais adequada. 
Como resultado da inadequação da proposta, nenhum dos textos produzidos pelos alunos se configura como "narração" e sim como "argumentação", conforme tipologia apresentada por Marcuschi (2002). Os alunos empregam diversas estratégias para atribuir sentido à proposta da professora e, consequentemente, constroem textos em que fundamentam seus sonhos em sequências argumentativas por natureza. Talvez intuitivamente, eles nem tentam obedecer ao comando de "escrever uma narração", dada a natureza da temática e considerando a dificuldade trazida pelo verbo no futuro ("será"), uma vez que o futuro diz respeito à realização do sonho e não ao sonho em si, que é mais bem descrito no tempo presente, como faz o texto abaixo.

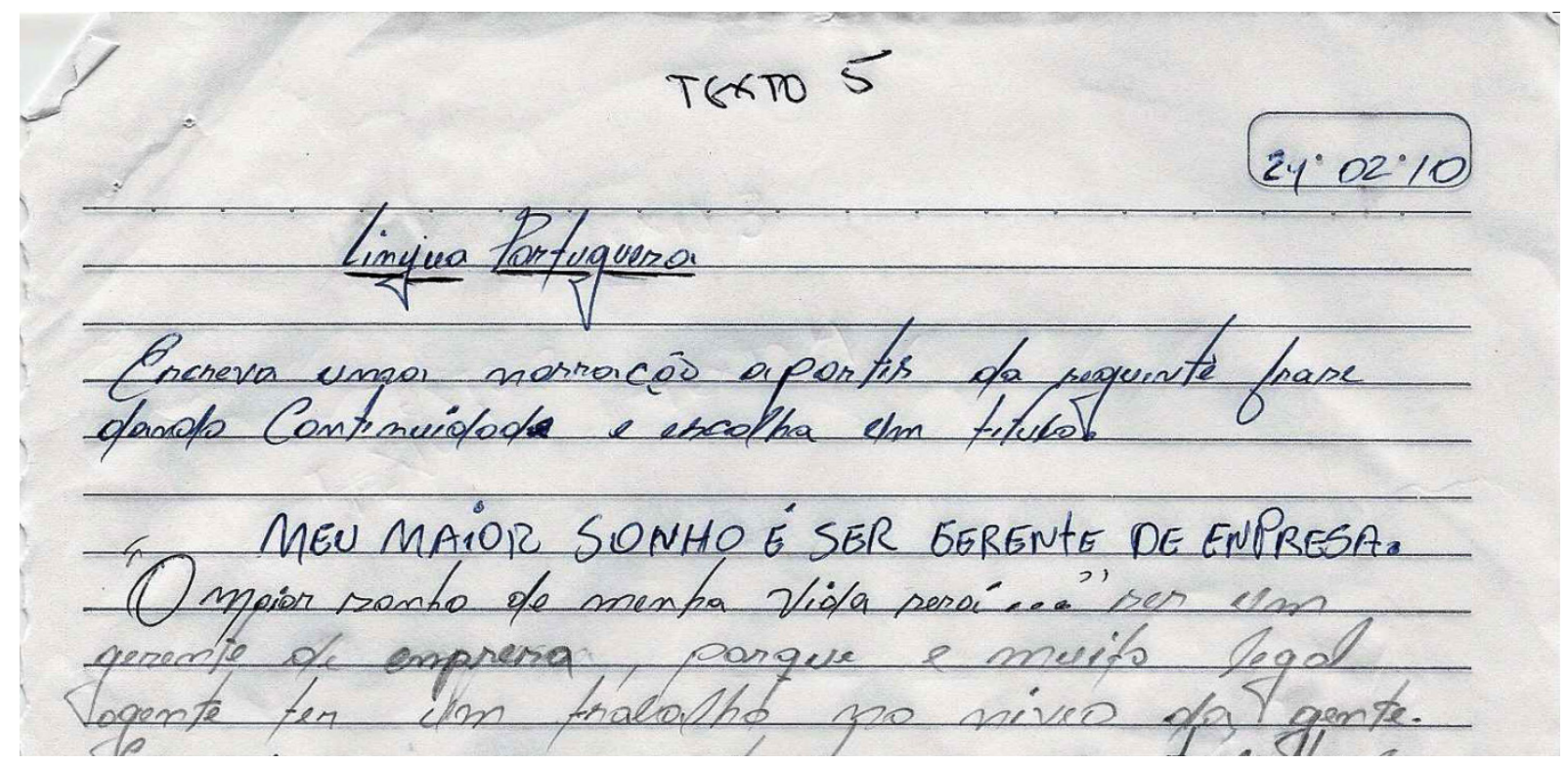

Observe-se que o aluno altera, no título, a forma verbal para o presente "é", embora mantenha a frase dada pela professora como início do texto, talvez por não se atrever a modificar consciente e explicitamente a proposta. Nesse parágrafo inicial, a sequência argumentativa (e não "narrativa”) se apresenta na forma de uma fundamentação do sonho de "ser um gerente de empresa": "porque é muito legal agente ter um trabalho no níveo da gente".

A análise da aluna-pesquisadora confirma e até elogia a construção da sequência argumentativa, omitindose mais uma vez de relacionar o texto efetivamente produzido com a proposta de produção, que solicitava, como visto, uma narração. De acordo com a aluna, o texto:

... é o que mostra coerência por comunicar a ideia central do autor, respaldado em considerações lógicas ou argumentos convincentes sobre o processo de como chegar a realizar o seu sonho. Existe um nexo, uma relação, uma harmonia entre as partes... Nos argumentos utilizados pelo autor, as relações entre os fatos presentes são pertinentes e estabelecem uma sequência lógica argumentativa...

Nota-se ainda certa fixação na análise dos traços mais superficiais da escrita dos alunos. No exemplo, vejase o texto produzido pela aluna e o comentário feito como análise por parte da pesquisadora:

\section{Texto da aluna:}

O meu sonho é ser empresária porque eu quero e sei que um dia eu vou alcançar esse obstáculo eu quero estuda cada dia mais porque sem o meu estudo eu não sou nada como eu quero ser empresaria eu tenho que estuda bastante. fazer uma faculdade primeiro o vestibular depos a faculdade. eu sei e tenho certeza que o meu sonho é ser empresaria e Deus vai me dá essa oportunidade de alcançar o meu obstáculo.

Sonhar como é bom.

Comentário da pesquisadora: 
O texto de n. 17 inicia com uma compreensão geral do que o autor pretende alcançar, com um problema de vocabulário - "o meu sonho é ser empresária porque eu quero e sei que um dia eu vou alcançar esse obstáculo”. Aqui aparece uma confusão de sentido, o que demonstra que o vocabulário do autor carece da ajuda de um dicionário para que possa estabelecer de maneira clara e concisa os seus objetivos.

Em se tratando de uma monografia cuja proposta era analisar a coerência textual, diversos aspectos poderiam ter sido levados em conta e incluídos no estudo. Entretanto, a pesquisadora deixa de se concentrar na coerência como "princípio de interpretabilidade do discurso" (CHAROLLES, 1983) e prefere destacar o uso de um único vocábulo que, convenhamos, poderia fazer bom sentido se o tex to fosse encarado da perspectiva de um leitor mais colaborativo, mais determinado a coconstruir os sentidos possíveis. Como se verifica do texto da aluna, "alcançar esse obstáculo", para ela, corresponde a superar os obstáculos que a separam de seu sonho. O problema aí constatado não é suficiente para configurar uma "confusão de sentido", nem é boa descrição do problema afirmar que "o vocabulário do autor carece da ajuda de um dicionário". Como se vê, se o texto da aluna mostra uma dificuldade mais ou menos localizada, a redação acadêmica da pesquisadora, por sua vez, não se mostra menos adequada.

\section{CONSIDERAÇÕES FINAIS}

A julgar pelos aportes teóricos apresentados pelos Novos Estudos do Letramento, que se recusam a avaliar a leitura e a escrita no Ensino Superior por uma perspectiva de déficit ou remediação e, considerando-se os resultados desta pesquisa, tudo indica que a Universidade não tem cumprido bem o seu papel de ajudar os alunos na aquisição e domínio do discurso acadêmico e de seus gêneros. De fato, o estudo permite perceber como os próprios alunos manifestam grande insegurança na produção, mais do que na leitura, de gêneros acadêmicos. Por outro lado, isso não significa que os estudantes não apresentem dificuldades com atividades de leitura, mas como, na maioria das vezes, essas atividades não são sistematicamente avaliadas em si mesmas e sim eventualmente na forma de produtos escritos, professores e alunos podem ficar com a impressão de que na leitura tudo está muito bem. No entanto, é cabível indagar se é possível apresentar problemas na escrita sem dificuldades correspondentes na leitura e vice-versa.

A primeira experiência dos alunos em estudos pós-graduados, representados pelo curso de Especialização, no caso específico relatado neste trabalho, não se deu sem percalços e nem sempre foi julgada por eles como um progresso notável em relação à graduação. Em alguns casos, os estudantes mencionam o "aprofundamento" havido em relação à graduação, enquanto noutros, reportam não ter tido contato com novos gêneros textuais quer na leitura quer na escrita. Embora isso possa não constituir uma informação precisa, o fato é que reflete um sentimento, uma percepção e uma insatisfação com respeito a essa etapa da formação acadêmica.

A análise especificamente textual indica que, apesar do contato com diversos gêneros acadêmicos, os estudantes encontram significativas dificuldades, em especial na escrita, sendo o exemplo mais crítico a produção da monografia de conclusão do curso. As dificuldades abrangem desde os aspectos mais superficiais, linguísticos e estruturais até questões mais centrais na pesquisa, como a constituição de corpora e os procedimentos de análise de dados, por exemplo. Para o estudante, a dificuldade, nesse caso, consiste em como passar de práticas de escrita acadêmica relacionadas quase exclusivamente com "ferramentas pedagógicas" para a produção de "gêneros científicos" (DIONÍSIO; FISCHER, 2010) como o projeto de pesquisa e a monografia no final do curso.

É certo que a leitura e a escrita dos alunos não se constituem apenas de aspectos problemáticos, embora não tenha sido o foco desta pesquisa evidenciar propriamente os aspectos positivos. Em todo caso, as práticas de escrita e leitura mais problemáticas, algumas das quais postas em relevo neste estudo, evidenciam a necessidade de um novo olhar, por parte dos professores da graduação e pós-graduação, sobre o processo de letramentos acadêmicos dos estudantes. Nesse processo e nessas práticas, a noção de gêneros acadêmicos 
continua ocupando lugar central e assim deveria ser encarada no ambiente universitário. Os letramentos acadêmicos se constituirão, essencialmente, como sinônimo de letramentos em gêneros textuais próprios do meio acadêmico, considerando-se não só o processo de aquisição de habilidades de leitura e escrita, nem a mera socialização na cultura universitária, mas fundamentalmente a negociação e a construção da identidade do aluno como membro e participante autorizado dessa/nessa cultura.

\section{REFERÊNCIAS}

BARTHOLOMAE, David. Inventing the university. In: ROSE, M. (Ed.). When a writer can't write: studies in writer's block and others composing process problems. New York: Guilford Press, 1985. p. 273-285.

BHATIA, Vijay K. Analyzing genre: language use in professional settings. London: Longman, 1993.

BERKENKOTTER, Carol; HUCKIN, Thomas. Genre knowledge in disciplinary communities. Hillsdale: Lawrence Erlbaum, 1995.

CHAROLLES, Michel. Coherence as a principle of interpretability of discourse. Text, v. 3, n. 1, p. 71-98, 1983.

DIONÍSIO, Maria de Lourdes; FISCHER, Adriana. Literacia(s) no ensino superior: configurações em práticas de investigação. In: CONGRESSO IBÉRICO "ENSINO SUPERIOR EM MUDANÇA: TENSÕES E POSSIBILIDADES”. Actas do... Braga: CIEd, 2010. Disponível em:

<http://repositorium.sdum.uminho.pt/bitstream/1822/10582/3/Dion\%C3\%ADsio\%20\%26\%20Fischer\%2 02010.pdf>. Acesso em: 31 ago. 2010.

FIGUEIREDO, Débora de C.; BONINI, Adair. Práticas discursivas e ensino do texto acadêmico: concepções de alunos de mestrado sobre a escrita. Linguagem em (Dis)curso, Tubarão, v. 6, n. 3, p. 413-446, set./dez. 2006.

HOFFNAGEL, Judith C. Gêneros discursivos e a universidade. In: HOFFNAGEL, Judith C. Temas em antropologia e linguística. Recife: Bagaço, 2010. p. 273-282.

JOHNS, A. M. Text, role and context: developing academic literacies. Cambridge: Cambridge University Press, 1997.

LEA, Mary R.; STREET, Brian V. Student writing in higher education: an academic literacies approach. Studies in higher education, v. 23, n. 2, p. 157-172, jun. 1998.

$\longrightarrow$ 368-377, 2006. Disponível em:

The "academic literacies" model: theory and applications. Theory into practice, v. 45, n. 4, p. $<$ http://www3.unisul.br/paginas/ensino/pos/linguagem/cd/English/22i.pdf> Acesso em: 26 ago. 2010.

MARCUSCHI, Luiz Antônio. Letramento e oralidade no contexto das práticas sociais e eventos comunicativos. Conferência apresentada no II Congresso Internacional da ABRALIN. Fortaleza, CE, 14 a 17 de março de 2001.

. Gêneros textuais: definição e funcionalidade. In: DIONÍSIO, Angela P.; MACHADO, Anna R.; BEZERRA, Maria Auxiliadora (Orgs.). Gêneros textuais e ensino. Rio de Janeiro: Lucerna, 2002. p. 19-36.

MILLER, Carolyn R. Gênero como ação social. Tradução de Judith C. Hoffnagel. In: MILLER, Carolyn R. Estudos sobre gênero textual, agência e tecnologia. Recife: Ed. da UFPE, 2009. p. 21-44.

RUSSELL, David R.; LEA, Mary; PARKER, Jan; STREET, Brian; DONAHUE, Tiane. Exploring notions of genre in "academic literacies" and "Writing Across the Curriculum": approaches across countries and contexts. In: BAZERMAN, Charles; BONINI, Adair; FIGUEIREDO, Débora (Eds.). Genre in a changing world. Fort Collins: The WAC Clearinghouse; West Lafayette: Parlor Press, 2009. p. 395-423.

STREET, Brian. Literacy in theory and practice. Cambridge: Cambridge University Press, 1984.

SWALES, John M. Genre analysis: English in academic and research settings. Cambridge: Cambridge University Press, 1990.

Research genres: exploration and applications. Cambridge: Cambridge University Press, 2004.

Recebido em 11/11/12. Aprovado em 07/o2/13. 